\section{ZOO NEWS}

\section{Making faces}

Italian researchers have found that

infant rhesus macaques can

imitate facial movements, suggesting that this ability isn't unique to great apes as previously thought.

Sticking your tongue out all day at baby monkeys? Now

that has to be one of the best jobs in the world.

\section{Live fast, die young}

The most distant galaxy isn't the only scientific record notched up this week (see page 128). Guinness World Records has confirmed that the coral reef pygmy goby (Eviota sigillata), discovered by Australian researchers, is the vertebrate with the shortest known lifespan - a fleeting 59 days.

\section{ON THE RECORD}

\section{(CExperience your own choice of a dazzling and varied array of gourmet food."}

Invitation for the official party of the 10th International Congress on Obesity in Sydney.

\section{'CTo vomit in space is not my idea of a good time.)}

Star Trek actor William Shatner turns down British entrepreneur Richard Branson's offer of a real space flight.

\section{OVERHYPED}

Last week, news sources worldwide reported that a parapsychologist at Trinity College, Cambridge, had proved the effect of telephone telepathy - in which a subject 'knows' who is calling before they answer the phone.

But the researcher, Rupert Sheldrake, is not employed by the university. Instead, he gets a grant from the Perrott-Warrick fund for psychic research, set up at Trinity about a century ago. The finances are still looked after by the college, but it has no connection with the committee that spends the money.

Martin Rees, master of Trinity, says it is inappropriate to describe Sheldrake's affiliation as Trinity College. "I think he's a former fellow of Clare, which should have undiluted credit," he says.

Sources: PLoS Biol., UPI

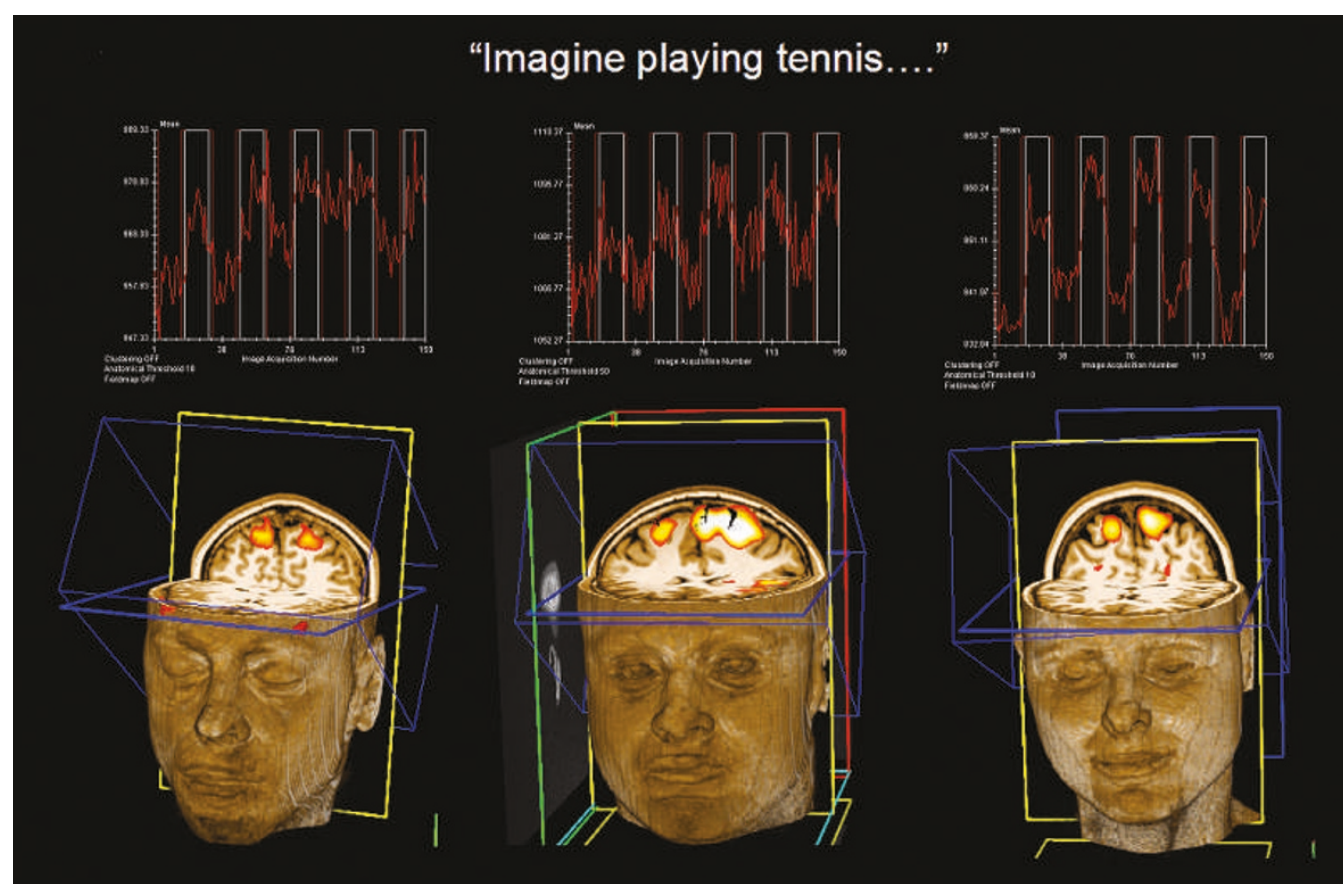

Brain areas activated in healthy volunteers (above) were identical to those in a vegetative patient.

\title{
'Vegetative' patient shows signs of conscious thought
}

The question of whether outwardly unresponsive patients may in fact be aware of their surroundings is one of the most heated debates in clinical neuroscience, with huge implications for the way such patients are diagnosed and treated. In a remarkable study published last week, researchers report that a patient who meets all the criteria of being in a 'vegetative state' can perform mental tasks on request. But the case highlights the difficulty of probing the mental state of an individual who cannot communicate, and of drawing any general conclusions about his or her condition.

Adrian Owen of the Medical Research Council's Cognition and Brain Sciences Unit in Cambridge, UK, and his colleagues used functional magnetic resonance imaging (fMRI) to scan the brain of a 23-year-old woman left in a vegetative state after a car accident in July 2005. Such patients do not respond to their surroundings, and doctors have always assumed that they are completely unaware of them. Previous brain-scanning studies have failed to detect more than reflex reactions to stimuli such as sound or pain.

Owen and his colleagues now show that their patient can respond to verbal requests to picture herself either playing tennis or walking around her house. Each activity produces a different pattern of brain activation, and these are strikingly similar to those of healthy volunteers (A. M. Owen et al. Science 313, 1402; 2006). The decision to comply with the experimenter's instructions proves awareness, says Owen. "What we've developed is a method for detecting when someone is aware in the absence of other clinical evidence."

But what that 'awareness' means is still up for debate. For example, Paul Matthews, a clinical neuroscientist at Imperial College London, argues that the brain imaging technique used cannot evaluate conscious thought; fMRI lights up regions of brain activity by identifying hotspots of oxygen consumption by neurons. "It helps us identify regions associated with a task, but not which regions are necessary or sufficient for performing that task," he says.

Matthews argues that the patient's brain could have been responding automatically to the word 'tennis', rather than consciously imagining a game. He also points out that in many vegetative cases, the patient's motor system seems to be undamaged, so he questions why, if they are conscious, they do not respond 
physically. "They are simply not behaving as if they are conscious," he says.

Owens counters that an automatic response would be transient, lasting for perhaps a few seconds before fading. He says his patient's responses lasted for up to 30 seconds, until he asked her to stop. He believes this demonstrates strong motivation.

He does admit, however, that it is impossible to say whether the patient is fully conscious. Although in theory it might be possible to ask simple 'yes/no' questions using the technique, he says: "We just don't know what she's capable of. We can't get inside her head and see what the quality of her experience is like."

If she is conscious, a pressing question is how many other vegetative patients might be in a similar condition. Here the uncertainty is even greater. A vegetative state can be triggered by a vast range of brain injuries, which vary widely in severity.

"Family members should not think that any patient in a vegetative state is necessarily conscious and can play tennis," says co-author Steven Laureys of the University of Liège, Belgium."It's an illustration of how the evaluation of consciousness, which is a subjective and personal thing, is very tricky, especially with someone who cannot communicate."

The patient studied by Owen's group, for example, seems to have been much less severely injured than the permanently vegetative Terri Schiavo, whose case inflamed the moral debate over whether those who show no signs of recovery should be allowed to die. Schiavo's feeding tube was

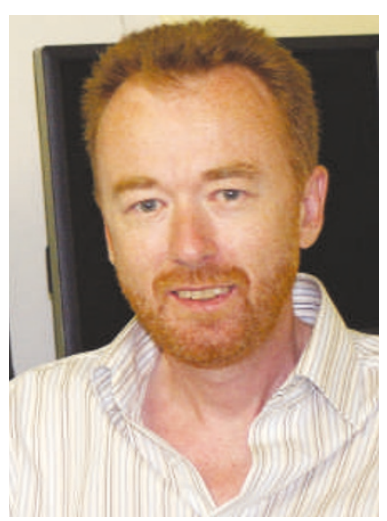

"What we've developed is a method for detecting when someone is aware in the absence of other clinical evidence." - Adrian Owen of injuries, and is now showing signs that she will recover, says Laureys. Since the research was carried out at the end of 2005, she has developed the ability to track her reflection in a mirror which suggests she is emerging into a 'minimally conscious state'. Laureys admits it is therefore possible that her brain scans merely heralded the early stage of her recovery, rather than providing real insight into the vegetative state. "We cannot exclude that she was in transition," he says. Another possibility is that the contact made during the study itself might have helped trigger the improvement - a factor that would raise the hope of being able to treat some cases. But that "remains pure speculation", says Laureys.

Either way, the case is likely to serve as a reminder to doctors that the vegetative state of patients should not be taken for granted. In 2003, another patient, Terry Wallis, stunned doctors by making a marked recovery after spending 19 years in a minimally conscious state. Neuroscientists later discovered that the neurons in his brain had been slowly reconnecting over the years, to bypass damaged regions (H. U. Voss et al. J. Clin. Invest. 116, 2005-2011; 2005).

Laureys believes that many patients may be slowly moving along a continuum from the vegetative condition, through minimal consciousness to full recovery. "As clinicians, we're obliged to reduce reality to a binary condition," he says. "We have to draw a line where there is actually a grey zone."

Neuroscientists have been trying for years to find firm evidence about awareness in vegetative patients. But removed in March 2005 after a legal wrangle.

Nevertheless, the research raises questions about whether the definition of a vegetative state should be changed to allow the possibility of using brain imaging to ascertain awareness. Currently, the condition is diagnosed if patients show no external awareness of themselves or their environment, although, in contrast to coma patients, their sleep-wake cycle is preserved. Typically, after a month the patient is judged to be 'persistently vegetative', and the condition is generally pronounced 'permanent' after a year without signs of recovery. The British and US legal systems then allow doctors to question whether the patient's treatment should be continued.

The British patient in the latest research seems to have been at the less severe end of the range previous studies using positron emission tomography have proved inconclusive. Four years ago, Laureys reported that although primitive brain centres in such patients were activated in response to a painful electric shock, the frontoparietal network, thought to be required for conscious perception, was not. This suggested that patients were unaware of the pain to which they had responded (S. Laureys et al. NeuroImage 17, 732-741;2002).

Studies using fMRI, which is thought to give a more accurate picture of brain activity, have been developed only recently. Owen says he hopes that real-time fMRI, which has become available since his latest study, will allow more sophisticated tests.

Michael Hopkin

See Editorial, page 121 